\title{
LA RENOVACIÓN RURAL EN LOS ESPACIOS DE MONTAÑA: LAS COMARCAS DE LA VERTIENTE NORTE DEL SECTOR CENTRAL DE LA CORDILLERA CANTÁBRICA
}

\author{
Carmen Delgado Viñas \\ Carmen Gil de Arriba \\ Dpto. de Geografía, Urbanismo y Ordenación del Territorio \\ Universidad de Cantabria \\ Luis-Alfonso Hortelano Mínguez \\ Juan Ignacio Plaza Gutiérrez \\ Dpto. de Geografía \\ Universidad de Salamanca
}

\begin{abstract}
RESUMEN
Este trabajo, que se integra en el programa de difusión de resultados de los proyectos de investigación en que se apoya, se centra en el análisis de los cambios que están experimentando en la actualidad las actividades productivas que constituyen la base económica de los espacios rurales periféricos de la Unión Europea. Se ha tomado como ejemplo el caso de un área del sector central de la vertiente septentrional de Montaña Cantábrica. Es un territorio formado por cuatro comarcas (Liébana, Cabuérniga-Tudanca, Valle de Iguña y Campoo-Los Valles) que comparten, además de su incuestionable situación periférica, un profundo y largo proceso de crisis y reconversión socioeconómica y espacial. La reestructuración presenta, no obstante, manifestaciones muy diversas, comunes en unos casos y distintas en otros: transformación de la actividad agraria y cambio en las orientaciones productivas ganaderas, expansión del sector de los servicios, en particular de los relacionados con el turismo y el ocio, declive de las actividades fabriles tradicionales, surgimiento de algunas nuevas industrias y auge de la construcción. Las diferencias en la intensidad, las pautas y el ritmo, de la evolución reciente de la actividad económica, se están traduciendo en la reorganización espacial y en el aumento de los contrastes y desequilibrios inter e intracomarcales.
\end{abstract}

Palabras clave: Transformaciones territoriales, terciarización, turismo rural.

1 Proyectos de Investigación BSO2000-1421-C02-01, BSO2000-1421-C02-02 y SA062/01 financiados, los dos primeros, por el Ministerio de Educación y Cultura - Secretaría de Estado de Educación, Universidades, Investigación y Desarrollo (Plan I+D+I 2000-2003) — y el tercero por la Consejería de Educación y Cultura de la Junta de Castilla y León (Programa de Apoyo a Proyectos de Investigación). Un resumen de este artículo ha sido presentado como comunicación a la XXIX Reunión de Estudios Regionales, celebrada en Santander los días 27 y 28 de Noviembre de 2003, bajo el título «La nueva dinámica económica y territorial de los espacios rurales periféricos: El caso del sector central de la montaña cantábrica». 


\begin{abstract}
This article that is integrated in the program of diffusion of results of the investigation proyectos in that is sustained, is centered in the analysis of the changes that are experiencing the productive activities that constitute the economic base of the spaces rural peripherals of the European Union at the present time. He has taken as example the case of an area of the central sector of the northern slope of Cantabrian Mountain. It is a territory integrated by four districts (Liébana, Cabuérniga-Tudanca, Valley of Iguña and Campoo-the Valleys) that share, besides their incues-tionable outlying situation, a deep one and I release crisis process and reconversión so-cioeconómica and space. The restructuring presents, nevertheless, very diverse manifestations, common in some cases and different in others: transformation of the you activi-give agrarian and I change in the orientations productive cattlemen, expansion of the sector of the services, in particular of those related with the tourism and the leisure, decline of the traditional industrial activities, emergence of some new industries and peak of the construction. The differences in the intensity, the rules and the rhythm, of the evolution re-ciente of the economic activity, they are translating in the space reorganization and in the increase of the contrasts and imbalances inter and intracomarcales.
\end{abstract}

Key words: Territorial changes, Terciarization, Rural Tourism.

\title{
1. Evolución reciente de la actividad agraria
}

Las transformaciones experimentadas durante la última década del siglo XX quedan bien reflejadas en los datos proporcionados por los dos últimos Censos Agrarios, el de 1989 y el de 1999, que han sido una de las bases documentales de nuestro análisis.

\subsection{Una reducción selectiva de las superficies de uso agrario}

A través de los datos censales se detecta una leve regresión de la superficie agraria censada: el conjunto de las explotaciones comarcales utilizaba 7.517 Ha menos en 1999 que diez años antes, lo que representa un porcentaje de retroceso de $-3,1 \%$, muy similar a la media del conjunto regional $(-3,6 \%)$. Sin embargo se perciben algunas diferencias internas significativas ya que los valores relativos son mucho más altos en algunos municipios de Campoo (Reinosa), Tudanca (Rionansa) y de Liébana (Vega de Liébana y Potes) $\mathrm{y}$, sobre todo, en la comarca de Iguña en la que la mayor parte de los términos experimentan pérdidas de superficie agraria censada muy grandes.

La merma más importante sigue correspondiendo a las tierras labradas. En todo el territorio considerado se cultivan hoy 810 Ha menos que en 1989, si bien la disminución porcentual, $-26,2 \%$, es inferior a la experimentada en el conjunto regional, $-40,6 \%$, ya que en estas áreas montañosas el proceso se había iniciado antes. Destaca el retroceso experimentado en Campoo-Los Valles hasta el punto de que en algunos municipios puede hablarse de una desaparición, o casi, del terrazgo cultivado en los últimos 10 años del siglo (Las Rozas, Campoo de Yuso, Campoo de Suso, Santiurde de Reinosa, Valdeprado), al igual que ocurre en otros de Iguña (Pesquera), de Cabuérniga (Polaciones, Peñarrubia, Rionansa, Tudanca) y de Liébana (Cillorigo, Cabezón).

La práctica totalidad de esa merma corresponde a las tierras dedicadas a cultivos herbáceos, un hecho que apenas presenta diferencias intercomarcales de relieve aunque sí intermunicipales. Aunque no cuantitativamente, desde un enfoque cualitativo es muy significativa la continuidad de la disminución de superficie dedicada al viñedo en Liébana. En el período 
considerado la regresión del viñedo ha sido considerable: en 1999 se han censado $31 \mathrm{Ha}$ menos, lo que implica una pérdida de $-63,3 \%$ y, en definitiva, la práctica desaparición de este cultivo al que ya sólo se dedican $18 \mathrm{Ha}$. Por el contrario, se observa un gran incremento relativo, sobre todo en Liébana, de las tierras dedicadas al cultivo de árboles frutales a los que se destinan ahora $80 \mathrm{Ha}$, la mayor parte en el Valle de Iguña y en Liébana.

En general se ha extinguido o reducido al mínimo el terrazgo en los términos más montañosos de todas las comarcas, con algunas excepciones escasamente expresivas, hasta el punto de que las tierras labradas no representan nada más que $1 \%$ de la superficie agraria censada en total, un porcentaje que sólo se supera en Valderredible y en Valdeolea.

Por el contrario, ha continuado produciéndose un aumento de la superficie de tierras dedicadas a pastos permanentes. En esta categoría se han censado 19.783 Ha más en 1999, lo que representa un incremento de $18,4 \%$ un poco menor que la media regional, con insignificantes diferencias intracomarcales. Como resultado de este proceso los pastos representan más de la mitad de las tierras censadas en la mayoría de los términos munici-

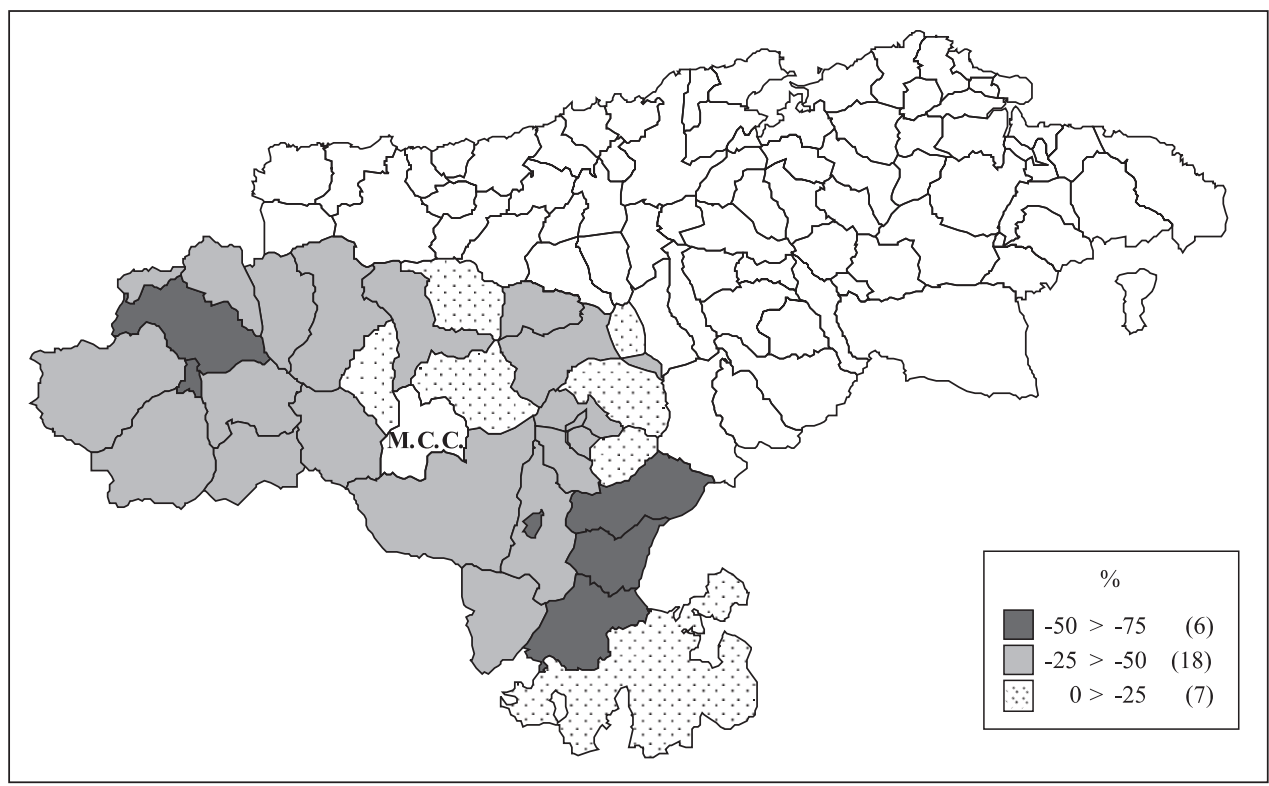

FiguRA 1. Evolución del número de explotaciones agrarias 1989-1999.

Fuente: INE, Censos Agrarios 1989 y 1999. Elaboración propia.

pales con la salvedad de algunos de Campoo (Valderredible y Campoo de Suso) y buena parte de los de Liébana y Cabuérniga en los que el predominio absoluto corresponde a las superficies forestadas.

\subsection{Una incompleta reestructuración de las explotaciones agrarias}

Hasta cierto punto la evolución reseñada está vinculada a otro proceso fundamental, una importante disminución del número de explotaciones agrarias. En 1999 se han censado 2.842 explotaciones menos que en 1989, lo que representa la desaparición del 38,2 \% de las existentes en esta fecha, un valor muy similar al del conjunto regional (-39,2\%) pero 
Tabla 1

EVOLUCIÓN DE LA ESTRUCTURA DE LAS EXPLOTACIONES AGRARIAS (\%)

\begin{tabular}{|c|c|c|}
\hline \multirow{2}{*}{ Superficie en Ha } & \multicolumn{2}{|c|}{ Años } \\
\cline { 2 - 3 } & 1989 & 1999 \\
\hline $0,1<5$ & 61,52 & 50,77 \\
\hline $5<10$ & 18,95 & 18,53 \\
\hline $10<20$ & 11,93 & 15,54 \\
\hline $20<50$ & 3,81 & 7,75 \\
\hline$>50$ & 3,79 & 7,42 \\
\hline
\end{tabular}

Fuente: INE, Censos Agrarios 1989 y 1999. Elaboración propia.

que oculta elocuentes diferencias intercomarcales. Así, mientras que en Cabuérniga e Iguña el porcentaje de disminución de las explotaciones ha sido bastante menor $(27,7 \%$ y 26,0 \% respectivamente), en Campoo ha sido de 42,6 \% y en Liébana de 41,8\%.

Como es lógico, la disminución del número de explotaciones ha conllevado un remodelado de las explotaciones, en cuanto a tamaño y distribución parcelaria, insuficiente en ambos aspectos.

Si bien es verdad que han desaparecido casi la mitad de las explotaciones más pequeñas, las de menos de $10 \mathrm{Ha}$, todavía continúa existiendo un número demasiado alto y teniendo un peso relativo muy elevado. Por otro lado, apenas ha aumentado el peso de las de 10 a $20 \mathrm{Ha}$ en tanto que sí ha crecido el número de las explotaciones pequeño-medianas, de 20 a $50 \mathrm{Ha}$, y su porcentaje; y lo mismo ha ocurrido con las mayores, de más de $50 \mathrm{Ha}$.

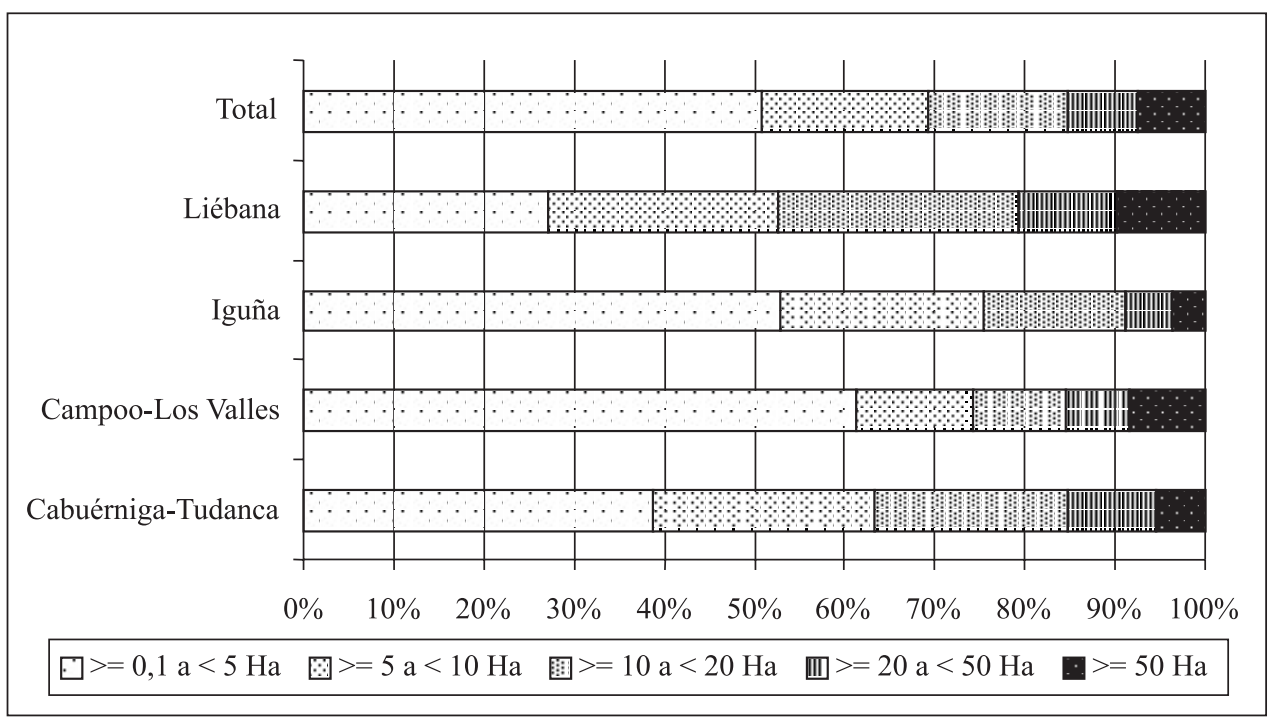

FiguRA 2. Estructura de las explotaciones con tierras en 1999.

Fuente: INE, Censos Agrarios de 1989 y 1999. Elaboración propia. 
En este aspecto también se perciben importantes diferencias intercomarcales en la evolución reciente: el mayor porcentaje de disminución de pequeñas explotaciones corresponde a Liébana y el aumento más significativo del porcentaje de explotaciones medias y grandes se ha producido en Liébana y en Cabuérniga-Tudanca. La desigual evolución explica las desemejanzas estructurales actuales, aunque todas las comarcas siguen conservando una estructura minifundista.

Por lo que se refiere a otro problema tradicional, la excesiva fragmentación parcelaria de las explotaciones, aunque ha disminuido el número total de parcelas en que se encuentra dividido el espacio de uso agrario, el porcentaje de disminución ha sido inferior al del espacio regional. La evolución reciente se ha manifestado en un crecimiento del número

Tabla 2

EVOLUCIÓN DE LOS REGÍMENES DE TENENCIA (\%)

\begin{tabular}{|l|c|c|c|c|c|c|c|c|}
\hline & \multicolumn{2}{|c|}{$\begin{array}{c}\text { Superficie en } \\
\text { Propiedad }\end{array}$} & \multicolumn{2}{c|}{$\begin{array}{c}\text { Superficie en } \\
\text { Arrendamiento }\end{array}$} & \multicolumn{2}{c|}{$\begin{array}{c}\text { Superficie en } \\
\text { Aparcería }\end{array}$} & \multicolumn{2}{c|}{$\begin{array}{c}\text { Sup. en otros } \\
\text { regímenes de } \\
\text { tenencia }\end{array}$} \\
\cline { 2 - 11 } & 1989 & 1999 & 1989 & 1999 & 1989 & 1999 & 1989 & 1999 \\
\hline Cabuérniga-Tudanca & 96,22 & 95,42 & 2,86 & 2,81 & 0,00 & 0,02 & 0,91 & 1,74 \\
\hline Campoo-Los Valles & 91,17 & 87,52 & 8,14 & 11,86 & 0,02 & 0,02 & 0,67 & 0,60 \\
\hline Iguña & 90,62 & 70,13 & 6,65 & 8,02 & 0,02 & 0,09 & 2,71 & 21,77 \\
\hline Liébana & 95,70 & 95,57 & 4,16 & 4,43 & 0,07 & 0,00 & 0,07 & 0,00 \\
\hline Total & 93,59 & 89,62 & 5,52 & 7,15 & 0,03 & 0,02 & 0,86 & 3,21 \\
\hline Cantabria & 83,72 & 80,43 & 13,54 & 14,60 & 0,04 & 0,10 & 2,69 & 4,87 \\
\hline
\end{tabular}

Fuente: INE, Censos Agrarios de 1989 y 1999. Elaboración propia.

medio de parcelas por explotación de forma que las explotaciones montañesas continúan estando muy parceladas: si en 1989 cada explotación tenía por término medio 14 parcelas, en 1999 reúne 21,8 parcelas frente a una media de 11,3 en la región.

El cambio estructural ha ido aparejado a una pequeña modificación del régimen de tenencia de la tierra ya que la reestructuración se ha producido sobre todo a partir de la disminución de la superficie agraria explotada en propiedad, tanto en valores absolutos como relativos, y del aumento de la superficie de tierras explotadas en arrendamiento, que ha experimentado un incremento del $25,3 \%$ respecto a las censadas en este régimen en 1989. El proceso ha tenido especial importancia en Campoo, hasta el punto de que en algunos municipios campurrianos las tierras arrendadas llegan a superar 1/5 de las explotadas (Campoo de Enmedio y Valdeprado del Río). Aún así, la proporción de tierras arrendadas sigue manteniendo en estas comarcas valores más bajos que en el conjunto regional.

\subsection{Una incipiente reorientación de la producción ganadera}

A pesar de la disminución del número de explotaciones agrarias, a lo largo de este tiempo se ha producido, de forma simultánea, el reforzamiento del potencial ganadero de 
estos espacios. Los datos censales reflejan el incremento en 18.374 Unidades Ganaderas (UG), lo que supone una ganancia del $31,1 \%$ frente al escaso crecimiento del total regional $(10.591 \mathrm{UG}=3,52 \%)$. Pero en este sentido también son muy acusadas las diferencias entre unas y otras comarcas montañesas: en Liébana apenas se ha modificado la carga ganadera con un pequeño aumento $(4,3 \%)$, mientras que en Campoo y Cabuérniga el progreso ha sido notable, tanto en valores absolutos como relativos $(28,7 \%$ y $36,55 \%$ respectivamente), y espectacular en el caso del Valle de Iguña $(62,56 \%)$.

A las desigualdades territoriales cabe añadir las referidas al tipo de cabaña ganadera. La cabaña fundamental en este espacio, la bovina, ha crecido mucho más que en otras áreas de la región. En todo el espacio montañoso considerado se han censado 12.239 UG bovinas más $(25,5 \%)$ frente al estancamiento de esta cabaña en la región $(0,96 \%)$. Pero la evolución ha presentado grandes desigualdades entre unas y otras comarcas: ha sido muy importante en Campoo (28,3 \%), Cabuérniga $(28,7 \%)$ e Iguña $(33,4 \%)$ y mucho más modesta en Liébana $(8,8 \%)$.

El progreso de la cabaña bovina no se traduce, sin embargo, en un aumento de su peso relativo en el conjunto de la cabaña ganadera que, incluso, ha disminuido de $81,3 \%$ en 1989 a 77,8 \% en 1999, en proporciones similares a lo que ha ocurrido en el conjunto regional. La explicación, como resulta evidente, no reside tanto en la evolución de la cabaña bovina como en la de las otras cabañas ganaderas. La de ovino ha tenido un gran incremento relativo en Iguña mientras que ha disminuido levemente en las otras comarcas; el caprino ha disminuido de forma generalizada; el porcino ha aumentado en Cabuérniga e Iguña al igual que el equino que ha experimentado un desarrollo generalizado $(40,92 \%)$ y muy homogéneo. La cabaña avícola ha empezado a tener una gran presencia en Iguña y, en menor medida, en Liébana.

En consecuencia la evolución reciente refleja un refuerzo de la actividad ganadera generalizada pero con modificaciones significativas respecto a la situación tradicional. La principal es la incipiente diversificación ganadera en el sentido de atenuación del predominio absoluto de la explotación bovina, en particular en el Valle de Iguña, pero también en Cabuérniga, en mucha mayor medida que en el conjunto regional donde el bovino sigue teniendo un peso abrumador (86,49 \% de las UG censadas). Aunque el bovino continúa siendo el ganado predominante en todas las comarcas, las diferencias entre unas y otras se han acrecentado, si bien dentro de un abanico muy reducido: 70,4\% de las UG del Valle de Iguña son bovinas frente al 84,8 \% en Campoo-Los Valles, la comarca que mantiene una especialización bovina mayor.

Los censos ganaderos elaborados por la Consejería de Ganadería del Gobierno de Cantabria a partir de los datos de las campañas de saneamiento avalan en términos generales los proporcionados por los Censos Agrarios expuestos hasta aquí. Según aquéllos, entre 1992 y 2001 la cabaña de vacuno de las comarcas montañosas estudiadas ha aumentado en 17.373 reses $(28,0 \%)$ mientras que el conjunto de la cabaña cántabra lo hacía sólo en un 8,5\%.

A escala comarcal, sin embargo, los datos entre unos y otros censos presentan acusadas diferencias. Los censos ganaderos reflejan un gran crecimiento de la cabaña bovina campurriana, en particular en los municipios de Hermandad de Campoo de Suso, Valdeprado del Río y Valderredible, algo menor en Cabuérniga, destacando el aumento del número de reses en los términos del alto Nansa (Tudanca), mientras que el aumento es mucho menor en Liébana y, sobre todo, en el Valle de Iguña, es especial en los municipios situados a mayor altitud.

Lo que agranda la importancia de este desarrollo es que se ha producido en paralelo una drástica reducción del número de explotaciones bovinas, aunque en menor proporción que en el conjunto regional (-24,72\% y $-35,2 \%$ respectivamente) sin que se aprecien acusadas 
Tabla 3

EVOLUCIÓN RECIENTE DE LAS EXPLOTACIONES BOVINAS

\begin{tabular}{|l|c|c|c|r|r|r|r|r|c|}
\hline & \multicolumn{3}{|c|}{ № de Reses } & \multicolumn{3}{c|}{ № de Explotaciones } & \multicolumn{2}{|c|}{ Reses/Explotación } \\
\cline { 2 - 11 } & 1992 & 2001 & $\begin{array}{c}\text { Dife- } \\
\text { rencia }\end{array}$ & 1992 & 2001 & $\begin{array}{c}\text { Dife- } \\
\text { rencia }\end{array}$ & 1992 & 2001 & $\begin{array}{c}\text { Dife- } \\
\text { rencia } \\
\%\end{array}$ \\
\hline Cabuérniga-Tudanca & 14.154 & 19.269 & 36,14 & 646 & 525 & $-18,73$ & 21,91 & 36,70 & 67,51 \\
\hline Campoo-Los Valles & 20.392 & 30.038 & 47,30 & 832 & 675 & $-18,87$ & 24,51 & 44,50 & 81,56 \\
\hline Iguña & 12.345 & 12.519 & 1,41 & 831 & 598 & $-28,04$ & 14,86 & 20,93 & 40,92 \\
\hline Liébana & 15.115 & 17.553 & 16,13 & 762 & 514 & $-32,55$ & 19,84 & 34,15 & 72,16 \\
\hline Total & 62.006 & 79.379 & 28,02 & 3.071 & 2.312 & $-24,72$ & 20,19 & 34,33 & 70,05 \\
\hline Total Cantabria & 308.946 & 335.307 & 8,53 & 18.487 & 11.984 & $-35,18$ & 16,71 & 27,98 & 67,43 \\
\hline
\end{tabular}

Fuente: Consejería de Ganadería, Gobierno de Cantabria. Campañas de Saneamiento.

Elaboración propia.

diferencias entre unas y otras comarcas ni entre términos municipales, con la salvedad de los que poseen condiciones naturales más difíciles (Pesquera y Bárcena de Pie de Concha en Iguña, Tresviso y Cabezón en Liébana) o los más urbanizados (Reinosa y Potes).

Como fruto de ambos procesos opuestos, ha tenido lugar un significativo incremento del tamaño de las explotaciones bovinas en términos de hato: de 20,2 cabezas de media por explotación en 1992 se ha pasado a 34,3 cabezas en 2001 de forma que el tamaño de las explotaciones de este espacio continúa siendo sensiblemente mayor que la media regional. Así, el tamaño medio de las explotaciones ha llegado a 44,5 cabezas en Campoo mientras que en Iguña tienen sólo 20,9 cabezas. Las explotaciones mayores corresponden a los municipios de Los Valles de Campoo y los de Tudanca.

Al mismo tiempo ha empezado a modificarse la orientación productiva de la cabaña bovina. A principios de la década de los noventa el predominio absoluto correspondía a las reses procedentes de cruces en Campoo e Iguña con un gran peso de las tudancas en Cabuérniga y de las pardo-alpinas en Liébana. Por el contrario, la cabaña frisona tenía poca importancia (19\% del total). En consecuencia, la cabaña de ordeño revestía escaso interés (32\% del total de las hembras de más de dos años) con alguna salvedad: el caso especial de Tresviso, en relación con la producción de queso, y algún municipio de Campoo e Iguña. Cabuérniga-Tudanca era la comarca con menos importancia del ganado de ordeño en tanto que el de no ordeño alcanzaba valores superiores a $80 \%$ y $90 \%$ en la práctica totalidad de los municipios de esta comarca.

En 1999 la cabaña frisona ha aumentado su volumen, pero su peso relativo sigue contenido en el 18,8\% aunque con cambios intercomarcales reveladores: mientras que ha aumentado su importancia en Liébana y algunos municipios campurrianos, en Cabuérniga y el Valle de Iguña ha disminuido el porcentaje de vacas holandesas. La causa fundamental ha sido el incremento generalizado del volumen y del peso relativo de la cabaña formada por reses procedentes de cruces con mínimas excepciones (Potes, Reinosa, Tresviso, Pesaguero y Camaleño), de forma que en la actualidad la cabaña de ganado cruzado supera la mitad del total (54\% frente al $46 \%$ de 1992). La cabaña pardo-alpina ha seguido sufriendo pérdidas tanto en valor absoluto como relativo y lo mismo sucede con la tudanca, con la excepción de algunos municipios lebaniegos y de Polaciones en Tudanca. 
Los cambios expuestos se han manifestado en una comedida modificación de la composición de la cabaña de vacuno por aptitud: la de no ordeño ha crecido de $68 \%$ a $73 \%$ mientras que la de ordeño ha tenido una pérdida generalizada de peso. Todo ello no hace sino expresar una importante reorientación productiva que es aún más evidente en la evolución de las explotaciones lecheras.

A partir de 1995 se ha producido una reducción generalizada del número de explotaciones que disponen de cuota láctea en mucha mayor medida que en el conjunto de la región. Como es lógico, esa disminución ha llevado aparejado el retroceso del volumen total de la cuota disponible en un valor relativo también superior al de la región que, en el mismo lapso de tiempo, ha aumentado la cuota. No obstante, las diferencias cuantitativas en la merma de ambos parámetros han redundado en un importante crecimiento del tamaño productivo de las explotaciones lecheras que ha aumentado en un 132,7 \%, algo más que la media regional. No obstante, las explotaciones lácteas de este área montañosa continúan siendo más pequeñas que las de otros ámbitos regionales.

En este sentido la evolución reciente ha producido importantes diferencias intercomarcales. En Cabuérniga-Tudanca ha subsistido un número muy reducido de explotaciones lácteas, y sólo en los municipios de Cabuérniga, Lamasón y Ruente, pero su dimensión media es relativamente grande. También en Campoo e Iguña la cuota media por explotación supera los $100.000 \mathrm{Kg}$. Por el contrario, en Liébana el proceso ha consistido en una reducción mucho mayor de la cuota disponible de forma que ha pervivido un número relativamente amplio de minúsculas explotaciones lácteas con una cuota media que no llega a $31.000 \mathrm{Kg}$. por explotación.

\subsection{Una substancial disminución y un leve rejuvenecimiento de la población activa agraria}

La transformación de la actividad agraria que manifiestan los cambios expuestos no ha implicado aumento del trabajo humano aportado ya que, en términos generales, ha disminuido el volumen de Unidades de Trabajo Anuales (UTA) aunque en menor proporción

Tabla 4

EVOLUCIÓN DE LAS EXPLOTACIONES LECHERAS

\begin{tabular}{|l|c|r|r|r|r|r|}
\hline \multirow{2}{*}{} & \multicolumn{2}{|c|}{ Evolución 1996/2002 (\%) } & \multicolumn{3}{c|}{$2001-2002$} \\
\cline { 2 - 8 } & $\begin{array}{c}\text { № explo- } \\
\text { taciones }\end{array}$ & $\begin{array}{c}\text { Cuota } \\
\text { total }\end{array}$ & $\begin{array}{c}\text { Cuota } \\
\text { media/ } \\
\text { explota- } \\
\text { ción }\end{array}$ & $\begin{array}{c}\text { No explota- } \\
\text { ciones }\end{array}$ & $\begin{array}{c}\text { Cuota } \\
\text { total } \\
(\mathrm{Kg})\end{array}$ & $\begin{array}{r}\text { Cuota } \\
\text { media/ } \\
\text { explota- } \\
\text { ción (Kg) }\end{array}$ \\
\hline Cabuérniga-Tudanca & $-81,48$ & $-10,32$ & 384,26 & 15 & 1.971 .616 & 131.441 \\
\hline Campoo-Los Valles & $-60,51$ & $-5,08$ & 140,36 & 139 & 14.970 .147 & 107.699 \\
\hline Iguña & $-63,50$ & $-19,49$ & 120,59 & 50 & 7.081 .827 & 141.637 \\
\hline Liébana & $-63,78$ & $-43,05$ & 57,25 & 113 & 3.493 .879 & 30.919 \\
\hline Total & $-64,06$ & $-16,37$ & 132,70 & 317 & 27.517 .469 & 86.806 \\
\hline Total Cantabria & $-45,48$ & 7,55 & 97,28 & 4.224 & 515.708 .963 & 122.090 \\
\hline
\end{tabular}

Fuente: Gobierno de Cantabria, Consejería de Ganadería, Estadísticas de Producción Animal. Elaboración propia. 
que en el conjunto regional (-22,2 \% frente a $-34,3 \%)$. La pérdida de empleo agrario ha sido mayor en Campoo (-38,3\%) y en Liébana (-20,9\%) que en Cabuérniga (-17,1\%) y sobre todo en Iguña $(-5,5 \%)$. No obstante, al haber sido más alto el porcentaje de disminución de las explotaciones, se observa una mayor aportación de trabajo en las explotaciones: en 1999 se utiliza una media de 0,75 UTAs por explotación frente a las 0,60 UTAs de 1989 aunque en ambas fechas los valores son inferiores a la media regional $(0,92$ y 0,85 UTAs respectivamente). En la actualidad las explotaciones lebaniegas son las que siguen consumiendo más trabajo (1,20 UTAs por explotación), seguidas muy de cerca por las de las comarcas de Cabuérniga-Tudanca e Iguña. Por el contrario, las explotaciones campurrianas continúan siendo muy extensivas y apenas han modificado la cantidad de trabajo utilizado, que es mínimo: 0,36 UTAs por explotación.

La disminución de la cantidad de trabajo agrario utilizada cobra mayor significado si cabe si la observamos a la luz de otros cambios experimentados por la población activa agraria, en particular por su grupo mayoritario, los titulares de las explotaciones.

En este sentido cabe resaltar un leve, aunque insuficiente y no generalizado, rejuvenecimiento de la población agraria. Entre ambos censos ha aumentado el porcentaje de empresarios más jóvenes aunque se siguen manteniendo valores inferiores a los de la media regional. También ha crecido la proporción de titulares con edades comprendidas entre 35 y 54 años al tiempo que ha menguado la de aquellos que tienen entre 55 y 64 años. Uno de los datos más expresivos es la disminución de los valores referidos a los titulares con más de 65 años, si bien el porcentaje de los que rebasan la edad de jubilación se mantiene 9 puntos por encima del valor medio regional. No obstante, el dato más alarmante, y el que sube la media del espacio considerado, es el elevado porcentaje de los titulares de explotación viejos de Campoo que se acerca a la mitad del total. Por el contrario, en Cabuérniga y Liébana se ha reducido mucho ese valor y se ha mantenido en Iguña, de forma que las tres comarcas presentan un reducido porcentaje de empresarios viejos, con valores de poco más de $1 / 5$ del total en los tres casos y siempre muy por debajo del conjunto cántabro.

Tabla 5

EVOLUCIÓN DE LA ESTRUCTURA POR EDADES DE LOS TITULARES DE LAS EXPLOTACIONES AGRARIAS

\begin{tabular}{|l|c|c|c|c|c|c|c|c|}
\hline & \multicolumn{2}{|c|}{ Hasta 34 años } & \multicolumn{2}{c|}{35 a 54 años } & \multicolumn{2}{c|}{55 a 64 años } & \multicolumn{2}{c|}{ de 65 años y más } \\
\cline { 2 - 10 } & 1989 & 1999 & 1989 & 1999 & 1989 & 1999 & 1989 & 1999 \\
\hline Cabuérniga-Tudanca & 5,94 & 11,44 & 27,11 & 41,35 & 33,26 & 24,78 & 33,68 & 22,43 \\
\hline Campoo-Los Valles & 4,29 & 5,90 & 19,75 & 27,25 & 29,50 & 19,11 & 46,46 & 47,74 \\
\hline Iguña & 11,50 & 12,74 & 36,02 & 45,07 & 30,88 & 20,41 & 21,59 & 21,78 \\
\hline Liébana & 7,98 & 11,09 & 24,51 & 44,53 & 29,61 & 21,60 & 37,91 & 22,78 \\
\hline Total & 6,18 & 8,77 & 23,90 & 35,27 & 30,23 & 20,63 & 39,70 & 35,32 \\
\hline Cantabria & 6,96 & 9,07 & 31,74 & 40,61 & 31,50 & 24,10 & 29,80 & 26,23 \\
\hline
\end{tabular}

Fuente: INE, Censos Agrarios de 1989 y 1999. Elaboración propia.

Los cambios afectan también a la dedicación laboral de los empresarios agrarios. Ha continuado la disminución generalizada del número de titulares que comparten la actividad agraria con otras actividades: en 1999 sólo un 16,5 \% mantienen otra actividad lucrativa principal; a ellos hay que añadir otro $2,3 \%$ que complementan la agraria con otra actividad 


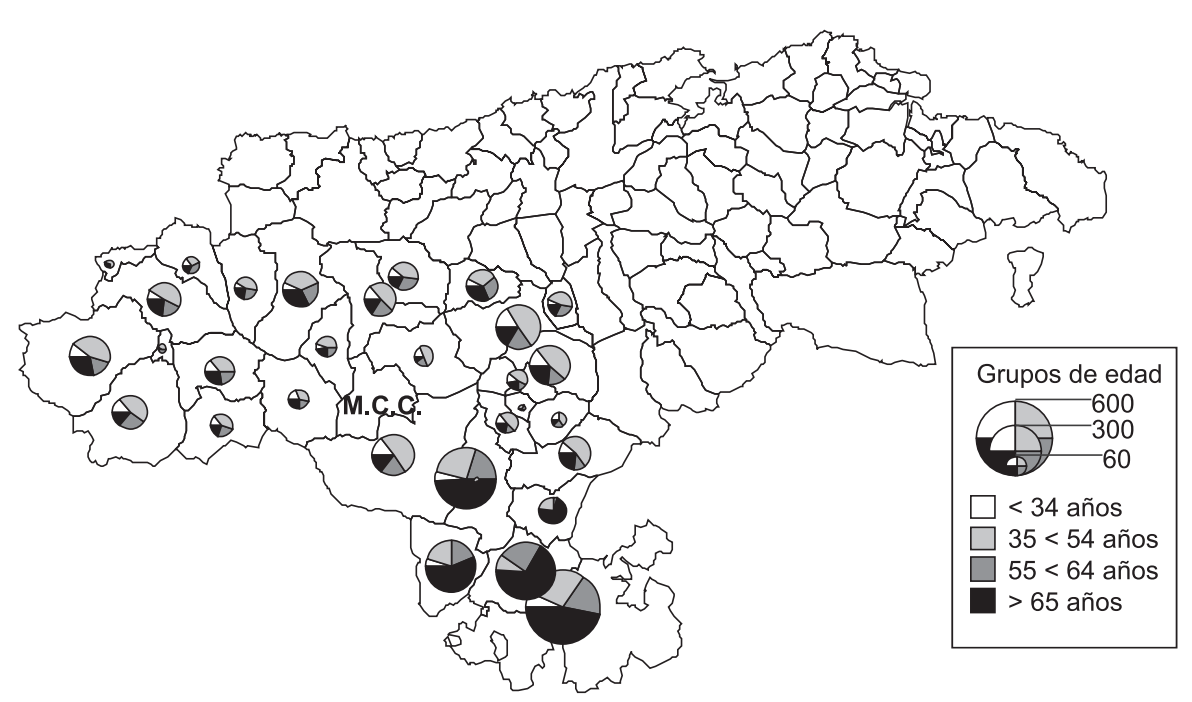

FIGURA 3. Estructura por edades de los titulares de explotación en 1999. Fuente: INE, Censo Agrario de 1999. Elaboración propia.

lucrativa secundaria. En total un modesto $18,8 \%$ de empresarios agrarios a tiempo parcial, un valor apenas inferior a la media regional, 20,5\%. La evolución reciente se ha traducido en una mayor homogeneidad intercomarcal. Así, si en 1989 casi la mitad de los titulares de los municipios del Valle de Iguña, el 46,5 \%, tenían otras ocupaciones remuneradas, principales $(39,3 \%)$ o secundarias, los valores casi se han igualado en 1999 con apenas diferencias reseñables entre el mínimo de Liébana, 14,4\%, y el máximo que sigue ostentando Iguña, 25,43\% (Bárcena de Pie de Concha todavía alcanza el 56,7 \% y Potes el $71,43 \%)$. Los valores mínimos corresponden a los términos más adentrados en la montaña y aislados (Lamasón y Polaciones en Tudanca, Santiurde, Valdeprado y Valdeolea en Campoo, San Miguel de Aguayo en Iguña, Vega y Pesaguero en Liébana).

La evolución detectada en la aportación humana de trabajo agrario se corresponde con los cambios que manifiesta la utilización de maquinaria en dicho trabajo. Evolución que en estos espacios de montaña apenas presenta diferencias con la experimentada por el resto de la región.

En primer lugar cabe resaltar que ha continuado el proceso de mecanización iniciado hace aproximadamente tres décadas. Dicho proceso se manifiesta en el aumento significativo del número de máquinas utilizadas a pesar de la reducción del volumen de explotaciones agrarias reseñada antes. En especial, y como máquina agraria más significativa, del número de tractores, que para todo el espacio considerado ha aumentado en un 11,1\% entre las dos fechas censales (19,6 \% en Cantabria). Lo que implica una media de 0,36 tractores por explotación en 1999 frente a 0,20 en 1989. Se trata, no obstante, de unos valores medios que ocultan grandes diferencias intercomarcales dado que, frente a la expresiva disminución del número de tractores usados en las explotaciones campurrianas, se ha producido un leve incremento en Iguña y un espectacular aumento en Cabuérniga y Liébana. Las diferencias están en relación con los modelos de explotación agraria que se van imponiendo en unas y otras comarcas, en particular con la progresiva sustitución de 
explotaciones agrícolas por ganaderas en Campoo y con la extensificación generalizada de las explotaciones ganaderas en Campoo e Iguña.

El avance del número de tractores se complementa con el retroceso de otro tipo de maquinaria utilizada hasta ahora habitualmente en la pequeña explotación ganadera (motocultores, motosegadoras, motoazadas, etc.). Su número ha disminuido de forma generalizada $(-36,25 \%)$ igual que en el resto de la región, en particular en Campoo. Refleja hasta cierto punto la sustitución de la pequeña maquinaria por máquinas de más potencia en las explotaciones algo mayores que van sobreviviendo.

Por otro lado, sigue teniendo escasa importancia también aquí otra clase de máquinas, como las cosechadoras de cereales, un tipo de maquinaria cuyo uso está disminuyendo al compás del retroceso de las tierras cultivadas dedicadas a herbáceos; en nuestro caso sólo se detecta una excepción poco significativa, la del Valle de Iguña.

\section{El avance de las actividades económicas no agrarias}

A partir de las conclusiones que pueden extraerse de lo expuesto hasta aquí, cabe afirmar que la oferta de empleo agrario resulta completamente insuficiente para mantener la actividad de la población montañesa, por más que se haya reducido mucho también.

Como apuntábamos en otro lugar ${ }^{2}$, resulta imprescindible desarrollar alternativas de empleo para la mano de obra disponible. Aquí, como en otros espacios rurales, la mayor parte de los empleos generados en las últimas décadas proceden de fuera del sector agrario. En términos generales puede decirse que el espacio montañés analizado está experimentando un proceso de crecimiento de las actividades económicas no agrarias durante la última década del siglo XX. Así parece deducirse de la evolución reciente del número de licencias para ejercer dichas actividades, que han aumentado en 5,6 \% entre 1992 y 2001 según los datos del Impuesto de Actividades Económicas (IAE) proporcionado por la Cámara Comercio, Industria y Navegación de Cantabria.

\subsection{Un proceso diferenciado territorialmente}

No obstante, el análisis más detallado de esa evolución en el decenio de los noventa presenta balances y situaciones muy contrastadas entre unas y otras comarcas. Puede afirmarse que el avance ha sido espectacular en el caso de Cabuérniga-Tudanca y muy importante, pero algo más moderado, en Liébana, frente al retroceso de Campoo-Los Valles y de Iguña. En valores relativos el crecimiento más espectacular ha sido el de los municipios de Pesquera, Peñarrubia, Los Tojos y Hermandad de Campoo de Suso que a lo largo de estos nueve años han aumentado el número de registros fiscales en más del $50 \%$. También hay que resaltar que, aunque el proceso de crecimiento afecta a la gran mayoría de municipios de este área, hay algunos que, por motivos diversos, parecen quedar al margen de las pautas generales de evolución a causa del estancamiento, o incluso de la regresión, de sus actividades económicas: ésta es la situación de Campoo de Enmedio, Arenas de Iguña, Lamasón, Reinosa, Valdeolea, Cieza, Anievas, Santiurde de Reinosa, San Miguel de Aguayo y Tresviso. Estos dos últimos, aunque parten de valores poco importantes (5 y 7 licencias cada uno), son los que experimentan los descensos más acusados, perdiendo el $40 \%$ y el $42,8 \%$ respectivamente.

2 DELGADO VIÑAS, C. (1997): «Crisis y reconversión en espacios rurales de montaña en Cantabria» en Ería, 44, pp. 335-357. 
Tabla 6

EVOLUCIÓN DE LOS REGISTROS DEL IAE EN EL SECTOR OCCIDENTAL DE LA MONTAÑA CANTÁBRICA

\begin{tabular}{|l|r|r|r|c|c|c|}
\hline \multirow{2}{*}{} & \multicolumn{2}{|c|}{1992} & \multicolumn{2}{c|}{2001} & \multicolumn{2}{c|}{$1992-2001$} \\
\cline { 2 - 7 } & № & $\%$ & № & $\%$ & № & $\%$ \\
\hline Cabuérniga-Tudanca & 330 & 11,47 & 414 & 13,62 & 84 & 25,45 \\
\hline Campoo-Los Valles & 1.576 & 54,76 & 1.559 & 51,30 & -17 & $-1,08$ \\
\hline Iguña & 351 & 12,20 & 343 & 11,29 & -8 & $-2,28$ \\
\hline Liébana & 621 & 21,58 & 723 & 23,79 & 102 & 16,43 \\
\hline Total Montaña Cántabra & 2.878 & 100,00 & 3.039 & 100,00 & 161 & 5,59 \\
\hline
\end{tabular}

Fuente: Cámara de Comercio de Cantabria. Impuesto de Actividades Económicas.

Elaboración propia.

Pese a la evolución reciente, apenas se ha modificado la tradicional situación de desigualdad en cuanto a la distribución espacial del volumen total y del peso relativo de las actividades económicas no agrarias que se desarrollan en las cuatro comarcas de referencia. Así, todavía más de la mitad de las licencias fiscales corresponden a Campoo, si bien su peso relativo ha menguado más de tres puntos porcentuales.

A escala municipal está aminorando también la situación de concentración anterior. En 1992 más de la mitad de las licencias se concentraban en sólo en tres municipios de los treinta y uno que componen este espacio: el término urbano de Reinosa — que por sí sólo concentraba exactamente un tercio de las actividades-, el municipio que envuelve al anterior y que puede considerarse funcionalmente como su prolongación, Campoo de Enmedio, con el $8 \%$ y Potes que abarcaba el $10 \%$ restante. A mucha distancia de los anteriores, y agrupando cada uno de ellos entre el $2 \%$ y el $5 \%$ del total de registros, se encontraban otros diez municipios: Arenas de Iguña, Molledo, Cillórigo de Liébana, Rionansa, Valdeolea, Valderredible, Camaleño, la Hermandad de Campoo de Suso, Cabuérniga y Ruente. Todos los demás quedaban muy por debajo, siendo elocuente el caso de los cuatro últimos: Pesquera, San Miguel de Aguayo, Tresviso y Lamasón con porcentajes inferiores al 0,5\% del compendio total de actividades sometidas a imposición fiscal.

A comienzos del siglo XXI la situación de reparto desigual ha cambiado poco ya que los tres municipios mencionados siguen concentrando el $46 \%$ del total de registros. El cambio, limitado pero elocuente, es consecuencia sobre todo de un ligero repliegue en el papel preponderante de Reinosa que, tras haber perdido un $9 \%$ el número de licencias fiscales respecto a la primera fecha, pasa a ostentar el 28,6\% del total de registros de las cuatro comarcas cántabras. Y lo mismo sucede en el municipio circundante, Campoo de Enmedio, que con un retroceso de $3 \%$, desciende al 7,3 \% en el mismo reparto. Sin embargo, Potes mantiene, e incluso incrementa levemente, su peso en el conjunto espacial. En la misma comarca de Liébana, Cillorigo y Camaleño también mejoran su posición relativa pasando, lo mismo que Rionansa y la Hermandad de Campoo de Suso, a superar el 4\% de la distribución del total de licencias de este área de la Montaña Cantábrica. En valores absolutos son precisamente estos términos los que han experimentado un incremento mayor del número de registros junto con Valderredible, Potes, Peñarrubia, Ruente, 


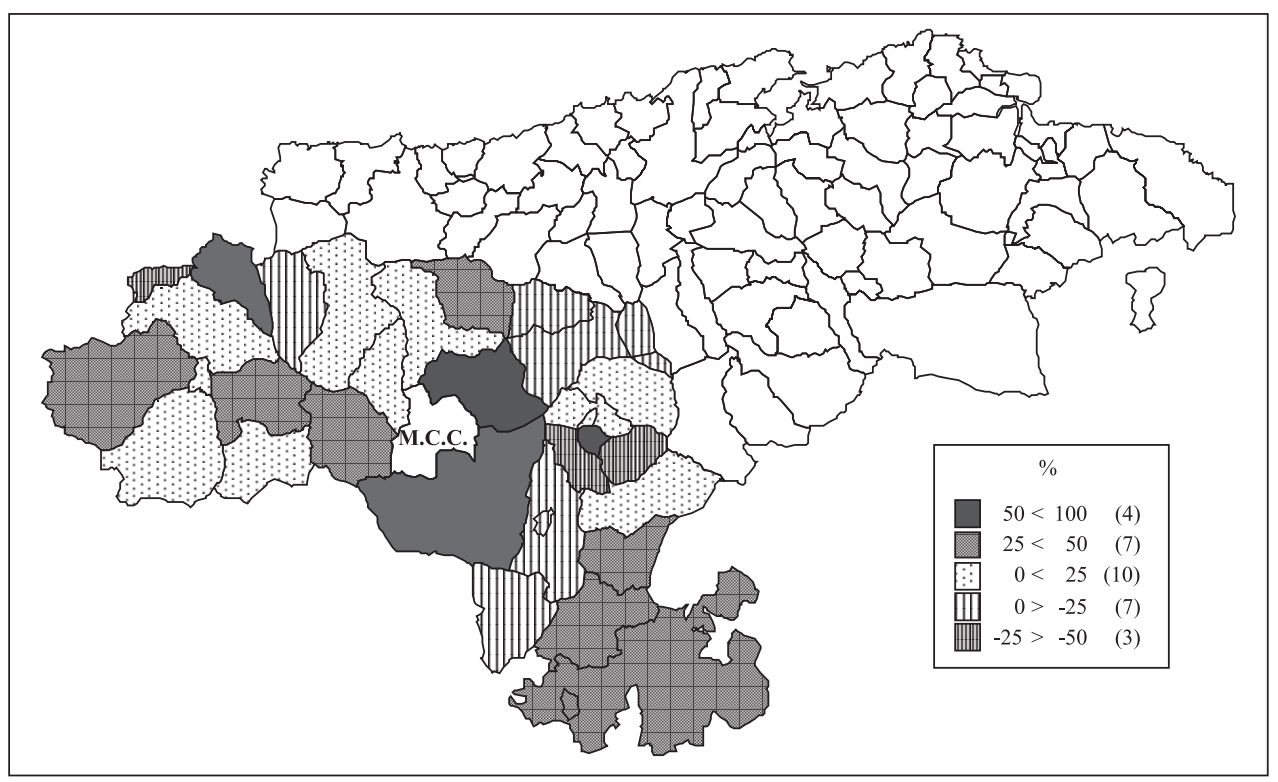

FIGURA 4. Evolución de las licencias para actividades no agrarias (1992-2001).

Fuente: Cámara de Comercio de Cantabria. Impuesto de Actividades Económicas.

Elaboración propia.

Los Tojos, Cabézon de Liébana, Cabuérniga y Vega de Liébana, todos ellos con más de diez apuntes más en 2001.

Como resumen puede decirse que los territorios más activos del área están siendo Cabuérniga-Tudanca y Liébana mientras que el Valle de Iguña y Campoo/Los Valles se presentan en conjunto como comarcas bastante menos dinámicas.

\subsection{Una paulatina terciarización de la economía rural}

Las diferencias territoriales se completan, y en gran medida se explican, con las desigualdades sectoriales ya que el incremento de las actividades no agrarias está resultando muy selectivo. A tal conclusión parece conducir la constatación del estancamiento o retroceso de algunas que durante años otorgaron a ciertos núcleos y municipios montañeses un perfil más industrial, mientras que avanzan a grandes pasos algunas actividades terciarias que, como el turismo rural y todo su complejo de actividades adjuntas, han irrumpido con fuerza en la Montaña.

Precisamente, pese a la imagen de declive generalizado extendida sobre la actividad industrial de las regiones cantábricas, el balance general de los últimos años en las comarcas analizadas es sólo ligeramente negativo. Si bien, de los tres epígrafes de actividad en que hemos agrupado el subsector industrial el número de registros ha decrecido en las industrias extractivas y manufactureras, en tanto que se ha producido un pequeño repunte de las licencias para industrias metálicas y para las actividades de producción, transporte y distribución de agua y energía.

Uno de los sectores de crecimiento más sobresaliente es el de la construcción, que en el conjunto del espacio considerado ha experimentado un incremento del número de licencias 
próximo al $24 \%$, destacando en particular el elevado número de registros en los epígrafes de albañilería y pequeños trabajos de construcción, reparación y conservación. Se trata de una actividad que se encuentra presente en casi todos los municipios, con excepción de Pesquera, San Miguel de Aguayo y Santiurde de Reinosa. Bien es cierto que cabe razonablemente pensar que la mayor parte de estas empresas realizan buena parte de su labor fuera del municipio en el que se hallan implantadas e incluso fuera de nuestro área de estudio, como, por ejemplo, en otros municipios próximos al litoral, donde los procesos de urbanización y edificación son mucho más acusados.

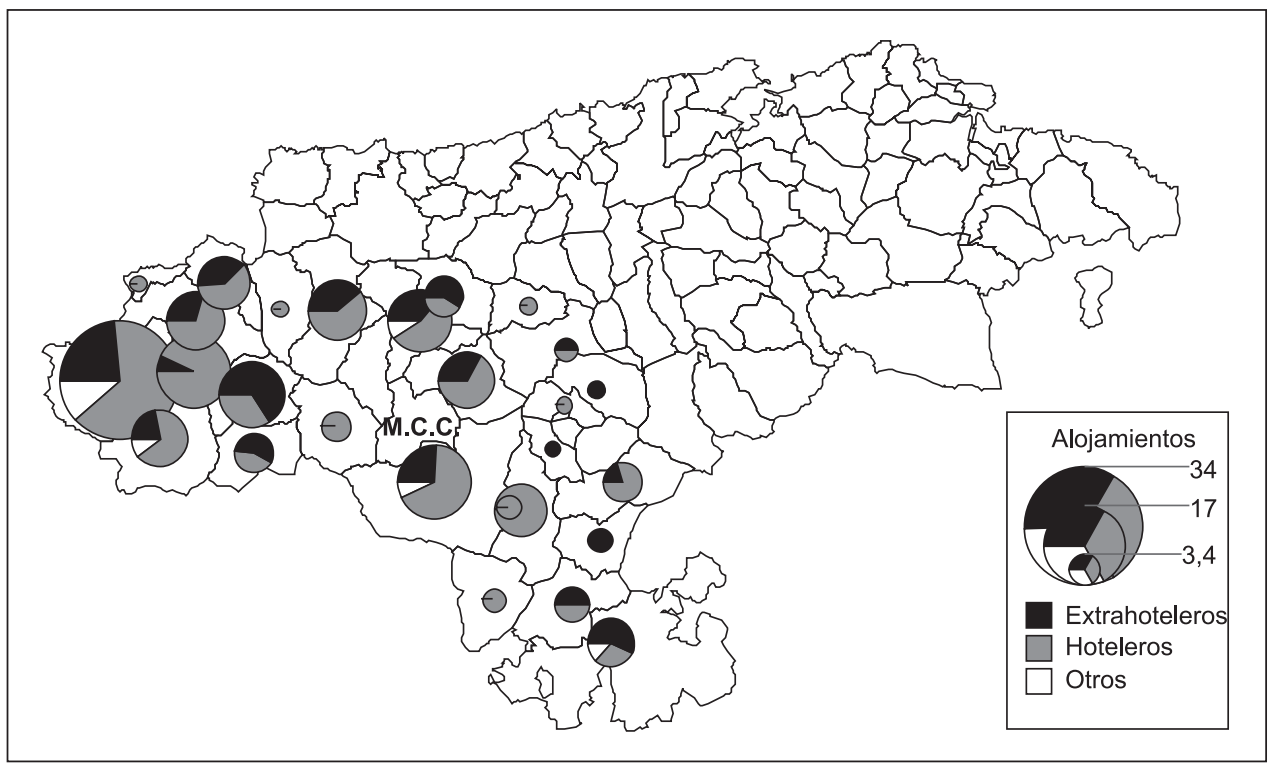

FIgURA 5. Distribución de las licencias para alojamiento en 2001

Fuente: Cámara de Comercio de Cantabria. Impuesto de Actividades Económicas. Elaboración propia.

También para el caso de las comarcas montañosas del Suroeste de Cantabria es preciso destacar el crecimiento de algunas actividades que, aunque englobadas en el conjunto de servicios financieros y servicios a las empresas, están relacionadas con la construcción; son las empresas inmobiliarias dedicadas a la promoción de edificaciones cuyo número ha crecido en un 71,4 \%, teniendo su localización principalmente en los municipios de Liébana - Potes, Camaleño, Cillorigo y Vega de Liébana- y en Reinosa/Campoo de Enmedio ${ }^{3}$.

Pero en estos momentos en todas las comarcas analizadas el peso fundamental de las actividades no agrarias se concentra en el subsector comercial, que reúne la tercera parte de todas las licencias fiscales en el año 2001; un porcentaje que ha disminuido levemente desde comienzos de los años noventa, cuando alcanzaba el 37,8 \%. Este hecho es el resultado de una tendencia, iniciada anteriormente y que se va consolidando, consistente en la disminución de estas actividades frente a lo que sucede con otras actividades del sector servicios.

El retroceso fundamental se ha producido en el subsector del comercio mayorista, en particular el relacionado con actividades agrícolas y ganaderas. En cuanto al comercio

3 Aunque muchas de estas empresas tienen sus domicilios fiscales en otras zonas de Cantabria como Santander y Torrelavega e, incluso, en Madrid. 
minorista, que es la rama de actividades no agrarias que más peso relativo sigue detentando, ha descendido en todas las comarcas, especialmente el de alimentación, el no especializado y el comercio ambulante, pero en proporciones mucho menores.

La evolución que resulta más espectacular, no obstante, es la de los servicios más estrechamente vinculados a las actividades de ocio y turísticas. En menor medida se trata de las actividades de restauración, bares y cafeterías, con un crecimiento medio apenas significativo ya que esconde un aumento del $60 \%$ en la cifra de restaurantes (su número ha pasado de 89 en 1992 a 143 en 2001) junto a un decrecimiento de 6,7\% en el de bares, el tipo de establecimientos más numeroso. Los municipios que concentran el mayor número de establecimientos son los campurrianos y lebaniegos, pero están avanzando muy rápidamente otros como Cabuérniga, Ruente y Los Tojos en los valles del Saja y del Nansa.

El crecimiento es incomparablemente mayor en cuanto a las actividades de alojamiento y hospedaje, sin lugar a dudas las actividades de servicios que experimentan un desarrollo más poderoso ya que el número de licencias creció un 103,3 $1 \%$ entre las fechas consideradas.

Tabla 7

DISTRIBUCIÓN DE LOS REGISTROS DEL IAE POR GRUPOS DE ACTIVIDAD

\begin{tabular}{|l|r|r|r|r|}
\hline \multirow{2}{*}{ Subsectores de Actividad } & \multirow{2}{*}{} & \multicolumn{2}{|c|}{ Diferencia } \\
\cline { 4 - 6 } & 1992 & 2001 & \multicolumn{1}{c|}{ № } & $\%$ \\
\hline INDUSTRIA & 240 & 231 & -9 & $-3,75$ \\
\hline Industrias extractivo-energéticas & 34 & 38 & 4 & 11,76 \\
\hline Industrias metálicas & 37 & 41 & 4 & 10,81 \\
\hline Industrias manufactureras & 169 & 152 & -17 & $-10,06$ \\
\hline CONSTRUCCIÓN & 406 & 502 & 96 & 23,65 \\
\hline COMERCIO & 1.087 & 1.022 & -65 & $-5,98$ \\
\hline Comercio mayorista & 147 & 107 & -40 & $-27,21$ \\
\hline Comercio minorista & 861 & 836 & -25 & $-2,90$ \\
\hline Intermediarios & 4 & 7 & 3 & 75,00 \\
\hline Reparaciones & 75 & 72 & -3 & $-4,00$ \\
\hline HOSTELERÍA & 562 & 685 & 123 & 21,89 \\
\hline Restaurantes, cafeterías, bares & 472 & 502 & 30 & 6,36 \\
\hline Hospedaje & 90 & 183 & 93 & 103,33 \\
\hline TRANSPORTES-COMUNICACIONES & 324 & 268 & -56 & $-17,28$ \\
\hline FINANZAS, SEGUROS, INMOBILIARIAS & 81 & 110 & 29 & 35,80 \\
\hline SERVICIOS VARIOS & 173 & 221 & 48 & 27,75 \\
\hline
\end{tabular}

Fuente: Cámara de Comercio de Cantabria. Impuestos de Actividades Económicas. Elaboración propia.

4 DELGADO VIÑAS, C., GIL DE ARRIBA, C., MÍNGUEZ HORTELANO, L. A. y PLAZA GUTIÉRREZ, J. I. (2002): «Actividades y usos extraagrarios en el sector central de la montaña cantábrica» en Los espacios rurales entre el hoy y el mañana, pp. 569-580. AGE/Universidad de Cantabria, Santander. 
Muy unidas al desarrollo reciente del turismo rural y a modalidades de alojamiento específicas, destaca la rápida evolución de los denominados «alojamientos turísticos extrahoteleros»: el número de registros de este epígrafe ha pasado de 4 a 58, lo que representa un aumento de $1.350 \%$, ubicados especialmente en los municipios lebaniegos (Cabezón de Liébana, Camaleño, Cillorigo, Pesaguero y Vega de Liébana), cabuérnigos (Cabuérniga, Los Tojos, Rionansa y Ruente) y algunos campurrianos (Hermandad de Campoo de Suso, Valderredible y Valdeprado).

Sin embargo no todas las actividades terciarias han sido igualmente expansivas en estas comarcas montañosas. Las que más han bajado son las de transporte y especialmente las de transporte de mercancías por carretera. Este descenso se halla muy vinculado con los cambios experimentados en las formas de transporte de la leche, como ya hemos puesto de manifiesto en otros trabajos efectuados para la zona oriental de Cantabria ${ }^{4}$. Así, los 239 registros que había en 1992 se reducen en un 19,2 \% en 2001. Pérdidas también importantes experimenta el número de licencias de autotaxi $(-25 \%)$ y de transporte de viajeros por carretera $(-16,7 \%)$ mientras que el de agencias de viaje, en relación con el desarrollo turístico, aumenta en un $400 \%$.

Es necesario, por último, resaltar que igualmente han experimentado un cierto impulso, pasando en varios casos casi a triplicarse, algunos servicios a empresas. Mientras que la evolución de los servicios bancarios ha sido levemente negativa, otros servicios de gestión han progresado decididamente.

Finalmente, en la categoría heterogénea de otros servicios, destacan los relacionados con actividades propias del medio rural, como son los servicios agrícolas y ganaderos y los servicios forestales. No obstante, disminuyen otros servicios colectivos sociales localizados en los municipios de mayor población, como los de enseñanza como consecuencia de las pérdidas de población, en particular en las edades más jóvenes. Por el contrario, los servicios sanitarios y asistenciales han experimentado un importante incremento (50 \%), lo mismo que los culturales $(68,2 \%)$ y los de limpieza y saneamiento de las poblaciones $(116,7 \%)$. La evolución positiva de estos últimos epígrafes, muy vinculados con los niveles de bienestar social, puede considerarse como un síntoma francamente esperanzador de las mejoras que están experimentando las condiciones y la calidad de vida de estos espacios rurales.

Teniendo en cuenta la evolución experimentada por el conjunto de actividades económicas no agrarias a lo largo de la última década, ha de subrayarse nuevamente, tal como apuntamos antes, el proceso de terciarización emprendido por estos espacios rurales, caracterizado por el auge de unos determinados servicios, especialmente los ligados a las actividades turísticas y de consumo. De ello se deduce que el proceso más nítido es la terciarización turística o turístificación de este área (empleando la expresión de G. Cazes), un proceso que responde más a lógicas, intereses y demandas foráneas, tendentes a la homogeneización de las cualidades y de la funcionalidad de los espacios rurales, que a las necesidades y vocaciones productivas de la propia población.

Es la terciarización turística la que explica la mayor expansión de la actividad constructiva y el extraordinario crecimiento de licencias de restauración y hospedaje, las dos arrastradas por los efectos generados por la promoción del turismo rural, necesitado de un notable incremento de la oferta de equipamientos. Las acciones de las iniciativas comunitarias Leader (I) y (II) y Proder han resultado decisivas en este sentido como hemos puesto de relieve antes en otros trabajos publicados sobre este espacio ${ }^{5}$.

5 DElgAdo VIÑAS, C., GIL DE ARRIBA, C., MíngUEZ HORTElAnO, L. A. y PLAZA GUTIÉRREZ, J. I. (2003): «La gestión turística de algunas comarcas de montaña cantábricas: una nueva imagen del territorio a partir de una utilización sostenible y de una oferta de calidad» en La geografía y la gestión del turismo, pp. 223-236. AGE/Universidad de Santiago de Compostela, Santiago de Compostela. 


\section{La evolución de la población como indicio de la dinámica económica y territorial}

La evolución de la población resulta un indicador bastante fiel de las transformaciones socioeconómicas y espaciales; en nuestro caso se cumple con bastante precisión esta circunstancia de forma que resulta casi imposible separar el proceso de reestructuración económica, expuesto antes, de la evolución demográfica reciente.

Tabla 8

EVOLUCIÓN DE LA POBLACIÓN DE HECHO 1950-2001 (\%)

\begin{tabular}{|l|c|c|c|c|c|}
\hline & $1950-1970$ & $1970-1981$ & $1981-1991$ & $1991-2001$ & $1950-2001$ \\
\hline Cabuérniga-Tudanca & $-27,76$ & $-21,20$ & $-14,78$ & $-1,92$ & $-52,42$ \\
\hline Campoo-Los Valles & $-23,57$ & $-4,63$ & $-8,75$ & $-10,82$ & $-40,68$ \\
\hline Iguña & $-8,97$ & $-11,25$ & $-9,17$ & $-13,01$ & $-36,16$ \\
\hline Liébana & $-31,95$ & $-19,15$ & $-13,21$ & $-1,98$ & $-53,19$ \\
\hline Total & $-23,77$ & $-10,60$ & $-10,28$ & $-8,79$ & $-44,23$ \\
\hline Total Cantabria & 15,39 & 9,35 & 3,81 & 0,91 & 32,19 \\
\hline
\end{tabular}

Fuente: INE, Censos de población. Elaboración propia.

La población del espacio montañoso considerado ha experimentado una extraordinaria merma desde mediados del siglo XX ya que en 50 años ha disminuido en algo más del 44 $\%$ al tiempo que la población cántabra en su conjunto aumentaba en un $32 \%$. Como consecuencia, se ha producido una continua pérdida de peso de la población de estas comarcas en relación con el volumen total regional: de ser el 16,7 \% en 1950 ha pasado a ser sólo el 7,0 \% en 2001, con todo lo que ello supone de menoscabo de la importancia sobre la adopción de decisiones político-administrativas.

La sangría más fuerte se produjo, como en la mayor parte de los espacios rurales españoles, hasta la década de los años setenta. Pero el hecho más significativo y grave es la continuación de las pérdidas con posterioridad y, en particular en los últimos años del siglo pasado. Así, entre 1981 y 1991 se ha producido una merma del 10,3 \%, prácticamente el mismo valor que en la década anterior, y, lo que es peor, en el último periodo censal, de 1991 a 2001, la reducción poblacional ha vuelto a ascender a $-8,8 \%$.

Por otro lado, la evolución poblacional reseñada presenta expresivas diferencias territoriales. La regresión demográfica mayor ha correspondido a las comarcas de Liébana y Cabuérniga-Tudanca que han perdido en el periodo de tiempo analizado algo más de la mitad de la población que tenían a mediados del siglo XX. Por el contrario, Campoo y el Valle de Iguña son las comarcas con menor merma relativa ya que la primera apenas rebasa el $40 \%$ y la segunda no llega a ese valor.

Pero, más que las diferencias totales, resultan relevantes las diferencias cronológicas. Las comarcas con cierto nivel de industrialización, como el caso de Campoo, y próximas a áreas industrializadas, como sucede con el Valle de Iguña, situado en el denominado Corredor Industrial del Besaya, perdieron menos población hasta los años noventa. Un hecho que hay que relacionar con la mayor posibilidad de empleo en la industria y con la práctica de la ganadería a tiempo parcial. La situación ha empezado a cambiar a partir del momento en que se inicia el proceso de reconversión económica de esas comarcas traduci- 
do en la pérdida de un elevado número de empleos industriales y en la disminución del número de «obreros mixtos». Así, los datos de los últimos censos muestran una clara inversión de la tendencia anterior: las mayores pérdidas de población en términos absolutos y relativos corresponden ahora a Campoo e Iguña, a gran distancia de Liébana y Cabuérniga cuya regresión poblacional, progresivamente atenuada, se sitúa en estos momentos en valores mínimos.

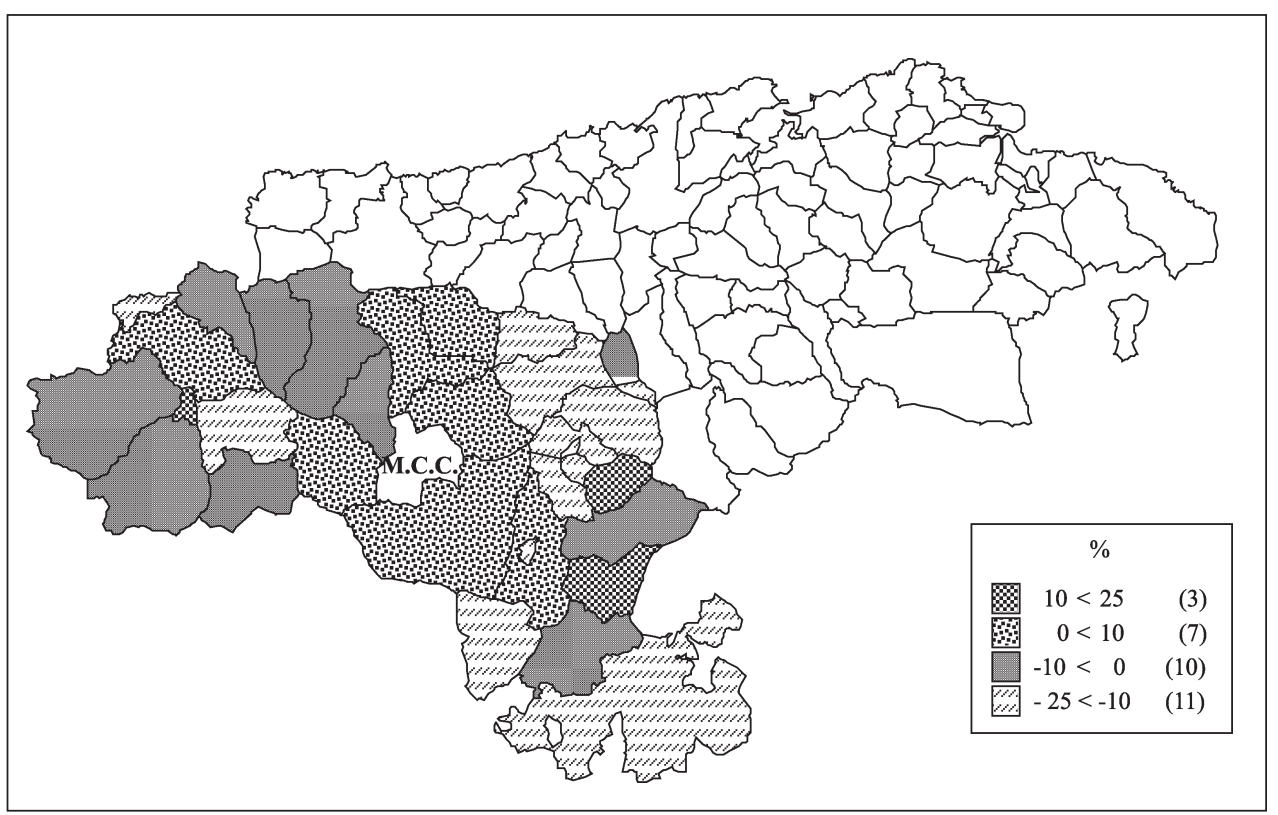

FiguRa 6. Evolución reciente de la población (1991-2001)

Fuente: Censos de Población de 1991 y 2001. Elaboración propia.

Las pérdidas mayores dentro de cada comarca corresponden a los municipios situados a mayor altitud y con peor accesibilidad, más aislados en definitiva: los de Tudanca en la comarca de Cabuérniga, Valdeolea y Valderredible en Campoo, Tresviso y Cabezón en Liébana y la mayoría de los de Iguña, en particular Pesquera, Cieza y Molledo. Un caso que requiere particular consideración es el de Reinosa, que ha perdido más de dos mil habitantes en el período comprendido entre los dos últimos censos $(-16,8 \%)$ como consecuencia del impacto del proceso de desindustrialización no compensado por el insuficiente desarrollo de su actividad terciaria como centro de servicios de una comarca en declive económico y demográfico.

Haciendo un balance general se llega a la conclusión de que sólo dos municipios han ganado población en la segunda mitad del siglo XX, Potes $(8,6 \%)$ y Reinosa $(13,2 \%)$, los dos en que se encuentran situadas las villas que han funcionado como centros de servicios comarcales. Otros dos han tenido pérdidas muy pequeñas, Ruente y Campoo de Enmedio, en relación con el mismo hecho ya que Ruente ha desempeñado una función similar en su comarca y Enmedio, en realidad, es un municipio indisociable del de Reinosa al que envuelve territorialmente.

El último decenio del siglo XX parece ser un tiempo de cambios, incipientes pero esperanzadores, como es la detención de las pérdidas poblaciones y el crecimiento, mínimo 
pero expresivo, en algunos términos de Cabuérniga (Los Tojos, Polaciones, Ruente, Cabuérniga), de Campoo (Hermandad de Campoo de Suso, Campoo de Enmedio, Las Rozas de Valdearroyo), de Liébana (Cillorigo además de Potes) y de Iguña (San Miguel).

\section{El claroscuro de la nueva dinámica territorial del espacio montañés}

En este espacio de montaña han tenido lugar en el último decenio del siglo XX intensos procesos de transformación económica con una proyección geográfica que subraya los contrastes internos. A los cambios que están contribuyendo a reestructurar la actividad y los espacios agrarios, impulsados fundamentalmente por las nuevas orientaciones eurocomunitarias, les ha acompañado la irrupción y paulatina implantación de usos no agrarios alternativos, que han ayudado a diversificar la estructura productiva de estas comarcas montañesas, y una evolución demográfica, estrechamente ligada a las mudanzas anteriores, que parece estar apuntando nuevas tendencias según los datos más recientes.

Cabe resaltar, en primer lugar, el valor ambivalente que presenta el proceso de reestructuración del sistema productivo agrario.

Si bien el terrazgo ha sufrido una significativa contracción, no está suponiendo un retroceso significativo de la superficie de uso agrario, por lo que no se percibe como una amenaza seria el abandono de las tierras explotadas con el consiguiente riesgo de deterioro. En realidad lo que se está produciendo es la continuación de la tendencia observada a lo largo de las últimas décadas de extensificación de usos: la mayor parte de las tierras labradas están siendo transformadas en prados y algunos prados en pastizales. Sí es cierto, sin embargo, que esos cambios representan una pérdida importante de la pluriactividad y diversidad agraria tradicionales y la desaparición de algunos de cultivos vinculados hasta ahora a la identidad de algunas comarcas, como es el caso del viñedo lebaniego y de las producciones de tubérculos campurrianas, en particular de Valderredible. En este sentido hay que afirmar que el espacio montañés tiende a homogeneizarse en la misma medida en que aumenta su especialización ganadera.

El refuerzo de la especialización pecuaria es visible en el aumento del potencial ganadero en un alto porcentaje y en una cierta tendencia a la diversificación como efecto del crecimiento simultáneo de todas las cabañas, aunque resulta especialmente significativo en el caso de la de ganado bovino, no sólo porque conserva un carácter dominante sino, sobre todo, porque su incremento en estas comarcas se produce coincidiendo con su estancamiento, incluso disminución, en otras comarcas de la región y en el conjunto regional.

$\mathrm{Si}$, en este aspecto, los datos manejados no permiten hablar taxativamente de un declive de la actividad agropecuaria, la importante disminución del número de explotaciones agrarias, por el contrario, parece indicar un claro retroceso del peso de la actividad agraria como base económica del espacio rural. Pero hay que considerar que la estructura tradicional, soportada en un elevado número de minúsculas explotaciones, resultaba inviable e insostenible en las nuevas condiciones en que se desenvuelve en la actualidad la actividad agraria, hasta el punto de que el proceso de reestructuración que está teniendo lugar es ineludible e, incluso, deseable.

En realidad, habida cuenta que la pérdida de SAU es mucho menor que la disminución de las explotaciones, lo que se está produciendo es un proceso de redimensionamiento de las explotaciones persistentes. Lo que redunda en una leve atenuación del minifundismo tradicional que resulta insuficiente si consideramos que todavía continúan teniendo un peso extraordinario las explotaciones muy pequeñas ( $85 \%$ con menos de $20 \mathrm{Ha}$ ), lo que es mucho más grave en el modelo de agricultura extensiva que se está imponiendo que en la más intensiva anterior. 
A esa rémora cabe añadir el inconveniente de la falta de corrección de otra deficiencia tradicional, la gran parcelación de las explotaciones. Un rasgo que no se atenúa en absoluto, sino todo lo contrario, ya que la forma de crecimiento de la superficie de las explotaciones es a través de la incorporación, en régimen de arrendamiento, de parcelas pertenecientes a explotaciones que van desapareciendo, en la mayoría de los casos no soldadas, ni siquiera próximas a veces, a las de la explotación a la que se añaden.

El redimensionamiento no se está produciendo sólo en el aspecto fundiario sino también en las dimensiones del hato de las explotaciones ganaderas. A ello está contribuyendo el refuerzo de la especialización ganadera y el aumento de la cabaña simultaneo al descenso del número de explotaciones. En la última década del siglo XX ha aumentado en más de un $70 \%$ el tamaño medio de los hatos de las explotaciones, pero, lo mismo que en superficie, la mayoría de las explotaciones ganaderas continúan siendo demasiado pequeñas para alcanzar un nivel adecuado de eficacia productiva, más aún cuando se trata, como es el caso, de explotaciones ganaderas de orientación cárnica que tienden a utilizar sistemas más extensivos.

Porque a estas transformaciones hay que añadir, igualmente, la reorientación reciente de la producción pecuaria que, más que una innovación, en realidad es una recuperación de la orientación tradicional. Estas comarcas montañesas mantuvieron durante siglos una economía agraria basada en una explotación ganadera extensiva y diversificada, aunque con primacía del bovino de labor. Sólo a partir de los años sesenta del siglo XX empezaron a adquirir importancia las explotaciones ganaderas dedicadas a la producción lechera. Una tendencia que parece liquidada en estos momentos ya que la evolución actual se orienta en el sentido del retroceso de la producción láctea intensiva y del avance de la producción cárnica extensiva. Así puede inferirse inequívocamente de dos hechos:

- El mayor crecimiento de la cabaña vacuna de no ordeño, que siempre fue más cuantiosa en estas comarcas que en el resto de la región y que ahora representa casi las tres cuartas partes de la cabaña bovina total.

- El decrecimiento más rápido de las explotaciones lecheras que las otras explotaciones vacunas (-64 \% de 1996 a 2002 las primeras y -25\% las segundas de 1989 a 1999). En estos momentos en el área estudiada pervive un número muy reducido de explotaciones lecheras si bien, con la excepción de las lebaniegas, se trata de explotaciones que rebasan, aunque sea levemente, el umbral de la viabilidad.

La incipiente modernización de las explotaciones ganaderas montañesas se manifiesta, igualmente, en la continuidad del proceso de mecanización iniciado unos años antes, como viene a demostrar el hecho de que el número de máquinas agrarias utilizadas, en particular el de tractores, ha seguido aumentando pese a la disminución del de explotaciones agrarias.

La maquinaria utilizada ha venido a complementar, en parte, la mengua de la población activa agraria. La desaparición de numerosas empresas agrarias se ha traducido en la reducción del empleo agrario si bien en una proporción menor. La diferencia entre ambos valores refleja un leve incremento en el trabajo aportado por explotación aunque es muy escaso ya que el valor medio no llega a 1 UTA por explotación en 1999.

Por otra parte, la disminución del volumen de la población activa agraria no ha ido acompañada de su necesario rejuvenecimiento. Sí es cierto que se ha reducido mínimamente el porcentaje de los titulares de explotación mayores de 55 años, pero también es verdad que no ha aumentado en la misma medida el de los más jóvenes. En consecuencia, bastante más de la mitad de las personas que se encuentran al frente de una explotación superan los 55 años y más de la tercera parte rebasa los 65; sobre todo en Campoo, la comarca que 
presenta un índice de envejecimiento más alto. Con estos datos, no es difícil suponer que el volumen de explotaciones va a seguir disminuyendo muy rápidamente en un breve plazo de tiempo, en cuanto se retiren definitivamente sus titulares sin que nadie los reemplace.

Es evidente que las pequeñas explotaciones agrarias no resultan suficientemente atractivas para la instalación en ellas de jóvenes ganaderos. En mayor medida aún hoy, cuando la compatibilización del trabajo agrario con otras ocupaciones laborales, que permitió hasta hace poco la supervivencia de muchas explotaciones poco rentables, ya no es un hecho frecuente. La práctica de la ganadería a tiempo parcial estuvo muy arraigada hasta los años ochenta, en particular en Campoo e Iguña, pero ha retrocedido mucho desde entonces: en 1999 sólo un $19 \%$ de los titulares de explotación siguen teniendo otra actividad, principal o secundaria, remunerada. Ese porcentaje medio apenas es rebasado ahora en Iguña, una comarca en la que hasta hace apenas diez años la mayor parte de los activos agrarios lo eran a tiempo parcial. La causa fundamental de ese cambio se encuentra en el retroceso de la actividad industrial de la propia comarca y, sobre todo, de las áreas industriales de Torrelavega y Reinosa que eran las que proporcionaban los empleos industriales a los «obreros mixtos» de estas comarcas rurales próximas. Las nuevas actividades no agrarias que se están implantando en ellas, a pesar a la fuerza con que se están desarrollando algunas, no ofrecen las mismas posibilidades.

Pero es quizás en el ámbito de las actividades no agrarias donde los cambios han adquirido mayor envergadura. Las comarcas estudiadas han empezado a experimentar recientemente un significativo proceso de reactivación económica que se manifiesta con claridad en el incremento del número de licencias para ejercer actividades no agrarias. Pero ese proceso ofrece grandes contrastes territoriales ya que se está produciendo un avance espectacular en Cabuérniga-Tudanca y de forma importante pero más moderada en Liébana, las comarcas que han conservado un carácter agrario más acusado hasta ahora, mientras que Campoo-Los Valles e Iguña, con una economía rural caracterizada desde hace décadas por un importante componente industrial, mantienen una dinámica económica levemente recesiva. Así, aunque la mayor parte de la actividad no agraria sigue radicando en Campoo, debido a la presencia abrumadora de Reinosa, se está iniciando un tímido proceso de disminución de la concentración espacial de dichas actividades más que de redistribución propiamente dicha.

Las desemejanzas en la evolución reciente parecen encontrar alguna explicación en los rasgos que definen el proceso de renovación de la base económica del espacio montañés en estos momentos.

Ese proceso, por una parte, es fruto del declive de las actividades sobre las que se sustentó la economía rural hasta hace poco, la ganadería y la industria. De la drástica reducción del empleo en la primera ya hemos dado cuenta y es, además, un hecho compartido con la práctica totalidad de los espacios rurales de montaña. Pero lo que resulta más peculiar es el fuerte impacto de la reconversión industrial que han sufrido algunas de estas comarcas, las que formaban parte de las cuencas de empleo de los núcleos industriales de Torrelavega-Los Corrales de Buelna, como es el caso de Iguña, y de Reinosa en el caso de Campoo-Los Valles. Bien es verdad que, frente al acelerado retroceso de la década de los ochenta, lo que se está produciendo en estos momentos es un estancamiento de la actividad industrial en las áreas donde antes tuvo mayor peso, lo que representa el inicio de un esperanzador cambio de tendencia.

Por otra parte, la reactivación es sobre todo el resultado del gran auge que empiezan a tener otros sectores de menor incidencia hasta ahora, sobre todo la construcción y las actividades de servicios de todo tipo, en especial las relacionadas con el ocio y el turismo que son, al igual que ha sucedido en otros espacios rurales, las encargadas de subrayar la marcada terciarización que está experimentando la economía de estas comarcas de montaña. 
Frente al estancamiento del comercio, pese a ser el ramo que conserva la mayor cifra de licencias, se ha producido un extraordinario crecimiento del número de establecimientos hosteleros, en particular de restaurantes de distintas categorías, y de alojamientos turísticos extrahoteleros. La proliferación de este tipo de servicios y de otros varios (inmobiliarios, financieros, de seguros, etc.), relacionados directa o indirectamente con aquéllos, nos permite afirmar sin temor al error que también en estos espacios de montaña está teniendo lugar un emergente e imparable proceso de terciarización.

En algunos casos el reciente desarrollo del terciario está contribuyendo a la diversificación de la economía rural basada en una combinación, mejor o peor ponderada, de la actividad agraria, la industrial y la de servicios. Es lo que parece estar sucediendo en Campoo e Iguña. En otros, como ocurre en Liébana y Cabuérniga-Tudanca, el desmesurado peso que están adquiriendo los servicios en la economía rural presagia una amenaza futura de «turistificación», entendida la expresión en el sentido de una excesiva dependencia, del territorio y de sus habitantes, de ese tipo de actividad.

La evolución económica reseñada, tal vez por su carácter incipiente, no ha logrado modificar de forma clara la dinámica demográfica regresiva que, desde mediados del siglo pasado, vació de efectivos humanos los pueblos de estas comarcas. Las cuatro comarcas consideradas sufrieron una importante sangría demográfica durante la segunda mitad del siglo XX, correspondiendo las pérdidas totales mayores a las comarcas que conservaron un carácter más marcadamente agrario y permanecieron menos accesibles, Cabuérniga-Tudanca y Liébana, que son también las que tuvieron valores de retroceso más altos hasta los años ochenta. Sin embargo, en el último período intercensal, coincidiendo con el proceso de renovación económica que estamos analizando, la tendencia ha empezado a invertirse radicalmente. Los valores más altos de descenso de la población corresponden ahora a CampooLos Valles e Iguña, las más golpeadas por los efectos de la desindustrialización y la reconversión productiva, mientras que Cabuérniga-Tudanca y Liébana han sufrido pérdidas insignificantes y muchos de sus municipios han aumentado, aunque sea en pocos, el número de sus habitantes. Y ello pese a que el crecimiento biológico es negativo en casi todos ellos, lo que otorga mayor elocuencia a la nueva situación. Aún así, la terciarización económica no parece estar ejerciendo como un factor que impulse claramente la fijación de la población y que, en consecuencia, actúe como causa de inversión de la tendencia al declive demográfico.

No obstante, aunque aún es pronto para sacar conclusiones terminantes, sí estamos en condiciones de afirmar que estos espacios rurales de montaña, como muchos otros, están empezando a experimentar cambios socioeconómicos significativos que parecen estar comenzando a modificar los rasgos de anquilosamiento y atrofia que han caracterizado a algunos de esos espacios hasta hace poco tiempo. Mutaciones que, por otra parte, están produciendo una homogeneización espacial que amenaza con acabar con la rica diversidad cultural y paisajística que han mantenido tradicionalmente las comarcas de montaña y que constituye, en definitiva, uno de los principales recursos sobre los que se sustentan las nuevas funciones terciarias que están adquiriendo estos territorios.

\section{Bibliografía}

CORBERA MILLÁN, M. (Ed.) (1999): Cambios en los espacios rurales cantábricos tras la integración de España en la Unión Europea. Santander, Universidad de Cantabria.

CORBERA, M.; FROCHOSO, M.; GONZÁLEZ, R. Y SIERRA, J. (1995): Saja-Nansa. Guía del Ecomuseo; Santander, Grupo de Acción Local «Saja-Nansa»; 2 vols.

DELGADO VIÑAS, C. (1996): «Procesos actuales de reorganización del sistema productivo agrario en espacios rurales de la montaña cantábrica»; en Actas del VIII Coloquio de Geografía Rural, pp. 97-108. Jaca, Asociación de Geógrafos Españoles-Universidad de Zaragoza. 
DELGADO VIÑAS, C. (1997): «Crisis y reconversión en espacios rurales de montaña en Cantabria» en Ería, 44, pp. 335-357.

DELGADO VIÑAS, C. (1998): «Cambios recientes en las orientaciones productivas de la ganadería bovina en Cantabria» en Actas del IX Coloquio de Geografía Rural, pp. 415-423. Vitoria, Universidad del País Vasco/AGE.

DELGADO VIÑAS, C. (1999a): «Avances y rémoras en el proceso de renovación de la explotación pecuaria en Cantabria» en Professor Joan Vilà Valentíl el seu mestratge en la geografía universitaria, pp. 875-889. Barcelona, Universitat de Barcelona, Barcelona.

DELGADO VIÑAS, C. (1999b): «La urbanización del campo en Cantabria» en El territorio y su imagen, pp. 1011-1021. Málaga, Universidad de Málaga/AGE.

DELGADO VIÑAS, C. (1999c): «Los procesos de difusión urbana en Cantabria» en Polígonos, nº 9, pp. 71-96.

DELGADO VIÑAS, C. (2000): «Changements récents des systèmes agraires dans les espaces ruraux de la Cantabrie (Espagne)» en Les nouveaux espaces ruraux de l'Europe Atlantique, pp. 48-61. Poitiers, Université de Poitiers.

DELGADO VIÑAS, C. y FUENTE ROYANO, M…T. de la (2000): «Las estrategias de desarrollo rural: una valoración del PRODER en Cantabria» en Los espacios rurales en el cambio de siglo: incertidumbres ante los procesos de globalización y desarrollo, pp. 723-734. Lleida, AGE/ Departamento de Geografía y Sociología de la Universidad de Lleida.

DELGADO VIÑAS, C. (2001): «La diversificación espacial de la ganadería bovina en Cantabria» en Espacio natural y dinámicas territoriales, pp. 409-422. Valladolid, Universidad de Valladolid.

DELGADO VIÑAS, C., GIL DE ARRIBA, C., HORTELANO MÍNGUEZ, L.A. y PLAZA GUTIÉRREZ, J.I. (2002): «Actividades y usos extraagrarios en el sector central de la montaña cantábrica» en Los espacios rurales entre el hoy y el mañana, pp. 569-580. Santander, AGE/Universidad de Cantabria.

DELGADO VIÑAS, C., GIL DE ARRIBA, C., HORTELANO MÍNGUEZ, L.A. y PLAZA GUTIÉRREZ, J.I. (2003a): «La gestión turística de algunas comarcas de la montaña cantábrica: una nueva imagen del territorio a partir de una utilización sostenible y de una oferta de calidad» en $L a$ geografía y la gestión del turismo, pp. 223-236. Santiago de Compostela, AGE/Universidad de Santiago de Compostela.

DELGADO VIÑAS, C., GIL DE ARRIBA, C., HORTELANO MÍNGUEZ, L.A. y PLAZA GUTIÉRREZ, J.I. (2003b): «Referencias indicativas de los procesos de cambio territorial en un espacio de montaña (Sector Central de la Montaña Cantábrica)»(Comunicación presentada al XVIII Congreso de la Asociación de Geógrafos Españoles, AGE; Barcelona, 24 al 27 de septiembre de 2003; en prensa).

DELGADO VIÑAS, C., GIL DE ARRIBA, C., HORTELANO MÍNGUEZ, L.A. y PLAZA GUTIÉRREZ, J.I. (2003c): «Turismo y desarrollo local en algunas comarcas de la Montaña Cantábrica: recursos y planificación»; Cuadernos de Turismo, nํ12, pp. 7-34; Universidad de Murcia.

GIL DE ARRIBA, C. (1998): «Programas europeos y desarrollo rural en Cantabria. Actuaciones y perspectivas»; en Polígonos. Revista de Geografía, 8, pp. 39-51.

GUTIÉRREZ GONZÁLEZ, S. (2000): «Balance de la aplicación de la iniciativa europea de desarrollo rural LEADER en Campoo (Cantabria)» en Los espacios rurales en el cambio de siglo: incertidumbres ante los procesos de globalización y desarrollo. Lleida, AGE/Departamento de Geografía y Sociología de la Universidad de Lleida, pp. 669-678.

ORTEGA VALCÁRCEL, J. (1989): «La economía de montaña, una economía de equilibrio» en Ería, no 19-20, pp. 115-128.

ORTEGA VALCÁRCEL, J. (2002): «Áreas de montaña: de la supervivencia a la integración» Conferencia pronunciada en las Jornadas sobre Patrimonio y Desarrollo en Áreas de Montaña, organizadas por la AGE, Oviedo, 14-16 de Noviembre, 2002 (texto fotocopiado).

PLAZA GUTIÉRREZ, J.I. (1993): «Desarrollo regional, medio ambiente y recursos naturales: reflexión teórica, valoración integrada y ejemplificación en las áreas de montaña (el caso de la región montañosa de la Cordillera Cantábrica)» en Actas del la XVIII Reunión de Estudios Regionales de la Asociación Española de Ciencia Regional (AECR), Universidad de Castilla-La Mancha, pp. 317-322. 
PLAZA GUTIÉRREZ, J.I. (2001): «Contrastes comarcales en la Montaña Cantábrica»; en Espacio natural y dinámicas territoriales (Homenaje al Dr. D. Jesús García Fernández) Servicio de Publicaciones de la Universidad de Valladolid; pp. 439-450.

PLAZA GUTIÉRREZ, J.I. (2003): «Changements récents dans les montagnes du Nord et du NordOuest de l'Espagne»; en Crises et mutations des agricultures de montagne. Presses Universitaires Blaise Pascal, Collection «CERAMAC», Clermont-Ferrand (France), pp. 659-674. 